Volume II, No.2 Desember 2012/1433 H

\title{
KONASI MASYARAKAT TERHADAP PENGGUNAAN ARABIC TERMS DAN DESKRIPSI FINANCE SCHEME DALAM PEMASARAN PRODUK BANK SYARIAH (Analisa Pada Masyarakat Kota Yogyakarta)
}

\author{
Abdul Ghani \\ (Dosen STAIS Dharma Indramayu)
}

\begin{abstract}
Sharia Banking in Indonesia have walked more or less two a decay and experience of the very growth of signifikan from year to year. But that progress not yet happened flattenedly. Because if comparated with the conventional bank growth is walked in advance mount the smaller that percentage a long way off. One of effort to increase enthusiasm of client of Indonesia Bank with the program of development of market segment and program the product development. During the time strive the product development of Sharia Banking more emphasizing at of service form and its transaction. Innovate to product of Sharia Banking even also is from time to time non-stoped to be developed and improved. Even to simply to differentiating characteristic among/between Sharia Banking with the conventional bank, crowded Sharia Banking embolden the islamication and arabication symbol and also its products. the symbol Eksklusivitas look coherent at name of product of Sharia Banking which always place forward the Arab terms (istilah-istilah arab), without reference to efficiency and the efektifity term use among plural society. Matter of that's becoming writer rationale to conduct this research

This research analyse the arabic terms what is a lot of used in product of Sharia Banking, later then comparate with the use of finance scheme descripition explored with the terms have Indonesian. This research take the sample of urban community of Yogyakarta because assessed to represent the strategic region. Pursuant to hypothesizing, there no willingness difference of society konasi to use of arabic terms and use of finance scheme description in a few its product. type of Sample research used by cluster random sampling. This type of used by because wishing to know there is do not it him difference of society willingness of according to background of education and profession type/work. Sample research as much 150 respondent which is taken away from some of urban community Yogyakarta. In analyzing data gathered to be used aid of analyzer of data SPSS 17. Research analysis conducted through/passing test of two related sample test with the test analyse the sign test, $k$-independent sample test with the test analyse the Kruskal Wallis, and the two-independent sample test with the test analyse the Mann Whitney U test.

Result of research show there are difference of society willingness to term use (arabic terms) and finance scheme description. Society more
\end{abstract}


wishing of finance scheme description to be used in product marketing of sharia banking compared by Arabic terms.

Keywords: arabic terms, finance scheme description, willingness, marketing, product.

\section{A. Pendahuluan}

Salah satu faktor yang cukup penting dalam mengkaji pengembangan bank syariah adalah melalui pengetahuan masyarakat terhadap keberadaan bank syariah. Dari hasil penelitian yang telah dilakukan oleh pusat penelitian kajian pembangunan lembaga penelitian Universitas Diponegoro (UNDIP) Semarang kerjasama dengan Bank Indonesia (BI) pada tahun 2000 dari sejumlah responden yang telah dihubungi di Jawa Tengah dan DI Yogyakarta terdapat 70,53 persen yang menyatakan bahwa mereka telah mendengar tentang Bank Syariah. Dalam penelitian tersebut disebutkan bahwa pengetahuan sebagian besar responden hanya berkisar pada nama Bank Syariah. Namun pengetahuan mereka tentang sistem dan produk bank syariah hanya sedikit sekali. Hal ini merupakan bukti kurangnya sosialisasi dari pihak bank syariah terhadap produk-produk bank syariah dan skim yang disediakan. Di samping itu adanya pemahaman masyarakat yang belum tepat terhadap kegiatan operasional bank syariah termasuk produknya merupakan salah satu kendala dalam proses pengembangan Bank Syariah. Untuk mengembangkan produk perbankan syariah agar mudah diterima di tengah masyarakat diperlukan informasi mengenai preferensi dan karakteristik masyarakat. Dalam rangka mengetahui karakteristik tersebut sekurang-kurangnya ada upaya untuk menggali informasi tentang faktorfaktor penting yang menjadi pendorong masyarakat dalam bertransaksi dengan lembaga keuangan terutama bank syariah serta pengetahuan mereka tentang sistem dan produk bank syariah (Puslit UNDIP, 2000).

Pembahasan mengenai pengembangan produk tidak lepas dari pemahaman tentang sistem pemasaran. Bagi dunia perbankan sistem informasi pemasaran dan riset pemasaran sangat besar peranannya dalam mencapai tujuan pemasaran bank (Kasmir, 2008). Dengan adanya sistem informasi yang baik akan memudahkan bank mengumpulkan dan menyaring informasi yang berkembang di luar bank. Salah satu informasi yang penting dalam hal ini adalah informasi yang datang dari masyarakat, karena mereka merupakan pangsa pasar yang akan dibidik menjadi nasabah. Oleh karenanya riset atau survei terhadap masyarakat merupakan suatu keniscayaan yang harus dilakukan oleh pihak Bank Syariah.

Kashmir (2008) menguraikan beberapa hal yang perlu dilakukan dalam sistem riset pemasaran yaitu; a) menilai kebutuhan informasi; yang meliputi informasi apa yang diinginkan dan informasi apa yang patut diberikan oleh bank untuk dapat diterima masyarakat secara luas; b) mengembangkan informasi; hal ini mencakup catatan intern, intelijen pemasaran dan riset pemasaran; c) mendistribusikan informasi kepada pihak-pihak yang membutuhkannya termasuk masyarakat secara umum. Jika sistem informasi pemasaran ini dijalankan dengan baik maka segala 
hal yang berkaitan dengan bank akan dapat beroperasi sesuai yang diharapkan.

Meskipun perbankan syariah mengalami perkembangan yang sangat signifikan dari tahun ke tahun, tapi jika dikomparasikan dengan perbankan konvensional yang telah berjalan lebih dulu tingkat prosentasinya masih sangat jauh tertinggal. ${ }^{1}$ Selama ini pemerintah melalui Bank Indonesia menerapkan beberapa regulasi, bahkan menargetkan pertumbuhan bank syariah dapat mencapai $5 \%$. Untuk mendongkrak pertumbuhan perbankan syariah agar dapat mencapai $5 \%$ Bank Indonesia telah mencanangkan program yang dirumuskan dalam sebuah Grand Strategi Pengembangan Pasar Perbankan Syariah (Zuhdi, 2009). Strategi itu merupakan polesan Bank Indonesia berdasarkan hasil survei, kajian dan analisis mendalam terhadap peta target market perbankan syariah di Indonesia dan berbagai faktor strategis. Berdasarkan Grand Strategy tersebut, ada 5 program utama yang dilakukan oleh bank syariah untuk dapat melakukan ekspansi pasar secara lebih luas, yaitu; a) program pencitraan baru, b) program pengembangan segmen pasar, c) program pengembangan produk, d) program peningkatan pelayanan, e) program komunikasi universal dan terbuka. Dari 5 program yang termuat dalam Grand Strategi tersebut program pengembangan produk merupakan salah satu program yang dapat dijadikan sebagai karakteristik tersendiri dan dapat membedakan antara perbankan syariah dengan perbankan konvensional. Program pengembangan produk inilah yang akan menjadi fokus penulis dalam melakukan penelitian.

Wahjono (2010) menyebutkan produk merupakan segala sesuatu yang dapat ditawarkan di pasar untuk mendapatkan perhatian, permintaan, pemakaian, atau konsumsi yang dapat memenuhi keinginan atau kebutuhan manusia. Contoh produk dalam perbankan konvensional seperti tabungan, deposito, kredit, giro dll. Sedangkan contoh sebagian produk dalam perbankan syariah seperti penghimpunan dana dengan 'aqad wadi'ah, produk pembiayaan/penyaluran dana dengan aqad mudlarabah, murabahah, ijarah dll (Muhammad, 2005; Antonio, 2001). Untuk menjadikan produk-produk tersebut sebagai produk yang diminati dan berkembang di tengah masyarakat sebagai calon nasabah tentunya diperlukan berbagai cara dan strategi pemasaran yang sistematik (Muhammad, 2005).

Selama ini upaya pengembangan produk perbankan syariah lebih menekankan pada bentuk jasa dan transaksinya. Inovasi terhadap produk bank syariah pun dari masa ke masa terus dikembangkan dan ditingkatkan. Bahkan untuk sekedar membedakan karakteristik antara bank syariah dengan bank konvensional, bank syariah ramai-ramai menggunakan simbol-simbol Islam dan Arab. Sehingga menjadi hal yang wajar ketika bank syariah mendapat stigma di masyarakat sebagai bank

Konasi Masy

\footnotetext{
${ }^{1}$ Data penelitian UNDIP mencatat perjuli 2000, di seluruh Indonesia terdapat 161 bank umum dengan jumlah kantor sebanyak 6.624 buah, dan terdapat 2.427 BPR, dengan jumlah total asset sebesar Rp. 970 triliun, kredit yang disalurkan sebesar Rp. 279,2 triliun dan dana masyarakat yang dihimpun Rp. 682,5 triliun.
}

JURNAL EKONOMI SYARIAH INDONESIA, Volume II, No.2 Desember 2012 
yang ekslusif, seolah-olah berlaku hanya untuk golongan muslim. Simbol eksklusivitas tersebut juga melekat pada nama-nama produk bank syariah yang selalu mengedepankan istilah Arab (arabic term), tanpa memandang efisiensi dan efektifitas penggunaan istilah tersebut di kalangan masyarakat majemuk. Padahal secara teoritis Antonio (2006) sebagai salah seorang pakar ekonomi Islam menyebutkan bahwa ciri lembaga atau perusahaan yang baik apalagi membawa nama syariah harus berorientasi pada empat hal, yaitu; inovasi, efisiensi, servis dan responsibilitas. Hal itu tentunya berlaku juga pada perbankan syariah sebagai lembaga bisnis. Lebih jauh Antonio (2006) menjelaskan bahwa dalam pemenangan marketshare, seorang marketer syariah selain harus terus berinovasi, juga wajib memperhatikan tingkat efisiensi. Meski di sisi lain inovasi memang sangat diperlukan terutama dalam inovasi produk. Karena keduanya saling berkaitan. Ellitan dan Anatan (2009) mengkonsepsikan inovasi sebagai perubahan yang dilakukan dalam organisasi yang di dalamnya mencakup kreatifitas dalam menciptakan produk baru, jasa, ide, atau proses baru. Dalam inovasi proses lebih menekankan pada metode-metode baru. Sedangkan dalam inovasi produk merupakan hasil dari penciptaan dan pengenalan secara radikal atau modifikasi produk yang telah ada.

Berkaitan dengan produk perbankan syariah tidak semua masyarakat memahami secara seksama tentang isitilah-istilah arab (arabic term) yang melekat pada produk bank syariah. Hal tersebut sejalan dengan apa yang disampaikan oleh Hermawan Kartajaya sebagai pakar marketing. Bahkan masyarakat santri pun yang identik pemahaman bahasa Arab-nya lebih baik di banding dengan masyarakat umum masih banyak yang tidak mengerti arti sebenarnya jika dihubungkan dengan produk bank syariah. Sementara di sisi lain penjelasan tentang skim keuangan (deskripsi finance scheme) sebagai substansi produk bank syariah merupakan keniscayaan yang perlu disampaikan oleh marketer bank syariah kepada masyarakat sebagai calon nasabah. Kemauan dan keinginan (konasi) masyarakat sebagai konsumen terkadang tidak sejalan dengan kehendak perusahaan sebagai produsen. Begitu pula dalam bank syariah kemauan dan keinginan (konasi) masyarakat belum tentu sejalan dengan ide arabisasi yang sering ditampakkan oleh bank syariah. Oleh karenanya dalam penelitian ini penyusun akan menganalisis perbedaan kemauan dan keinginan (konasi) masyarakat terhadap penggunaan istilah arab (arabic terms) dan deskripsi tentang skim keuangan (finance scheme) yang diungkapkan dengan bahasa Indonesia dalam pemasaran produk perbankan syariah. Sehingga dengan sendirinya akan diketahui pola mana yang lebih efektif dalam pemasaran produk bank syariah.

Kota Yogyakarta merupakan kota pelajar sekaligus kota budaya yang di dalamnya terdapat masyarakat majemuk. Sebagai kota pelajar, Yogyakarta merupakan tempat bertemunya para pelajar dan mahasiswa yang datang dari wilayah nusantara dengan latar belakang suku/ras dan agama yang berbeda untuk menimba ilmu pengetahuan. Bahkan tidak sedikit diantara mereka yang bernaturalisasi menjadi warga Yogyakarta. Sebagai kota budaya Yogyakarta sangat memegang nilai-nilai budaya jawa yang dikenal santun dan di dalamnya banyak terdapat tempat-tempat bersejarah sebagai warisan leluhur. Hal tersebut berpengaruh pada

Abdul

Ghani

158 
banyaknya turis baik domestik maupun asing yang berkunjung sebagai wisatawan. Sehubungan dengan hal-hal tersebut topik penelitian ini dibatasi pada judul; Analisis Perbedaan Konasi Masyarakat Terhadap Penggunaan Arabic Terms Dan Deskripsi Finance Scheme Dalam Pemasaran Produk Bank Syariah (Studi Pada Masyarakat Kota Yogyakarta).

Berdasarkan latar belakang penelitian sebagaimana tersebut di atas, permasalahan penelitian ini dapat dirumuskan sebagai berikut:

1. Apakah ada perbedaan kemauan masyarakat Kota Yogyakarta terhadap penggunaan arabic terms dan deskripsi finance scheme?

2. Pola mana yang lebih diinginkan masyarakat Kota Yogyakarta dalam pemasaran produk bank syariah?

\section{B. Tinjauan Pustaka}

Penelitian mengenai perbankan syariah telah banyak dilakukan oleh beberapa peneliti. Sebagaimana penelitian yang telah dilakukan oleh Pusat Penelitian Kajian Pembangunan Lembaga Penelitian Universitas Diponegoro Semarang (2000), yang mana penelitian tersebut memetakan potensi pengembangan jaringan perbankan syariah di wilayah Jawa Tengah dan DI Yogyakarta sekaligus mengidentifikasi karakteristik kelompok masyarakat di wilayah tersebut. Kemudian penelitian oleh Hamidi dkk (2000) tentang persepsi dan perilaku masyarakat santri Jawa Timur terhadap Bank Syariah. Dalam penelitian tersebut disebutkan beberapa faktor pendorong masyarakat santri dalam memilih Bank Syariah melalui pendekatan total produk dan pendekatan level produk. Kemudian penelitian oleh Lembaga Penelitian Universitas Andalas Padang (2001) tentang potensi, preferensi dan prilaku masyarakat terhadap Bank Syariah di Sumatera Barat. Penelitian tersebut menyebutkan bahwa meskipun sebagian besar responden mengenal lembaga keuangan syariah, namun pemahaman mereka tentang prinsip dan istilah-istilah yang digunakan dalam operasionalnya masih sangat rendah $(<30 \%)$. Penelitian-penelitian tersebut lebih banyak mengkaji pada sudut pandang preferensi masyarakat terhadap perbankan syariah secara global. Dari beberapa penelitian perbankan syariah yang ada, penulis belum menemukan penelitian yang spesifik dan fokus mengkaji efisiensi dan kemauan masyarakat terhadap penggunaan arabic term dan deskripsi skim keuangan dalam pemasaran produk perbankan syariah.

Arabic Terms berasal dari dua kata arabic dan term. Arabic dalam kamus bahasa Inggris artinya bahasa Arab, sedangkan term artinya istilah (Echols dan Shadiliy, 1996), sehingga secara etimologi arabic terms berarti istilah-istilah Arab. Arabic Terms (istilah-istilah Arab) yang dimaksud dalam penelitian ini adalah istilah-istilah fiqih terapan yang termuat dalam kajian fiqih mu'amalah yang berkaitan dengan 'aqad dan berhubungan dengan persoalan perbankan syariah. Istilah ini digunakan dalam dunia perbankan syariah sebagai prinsip dalam bertransaksi keuangan yang diaplikasikan dalam bentuk produk-produk bank syariah. Adapun 'aqad

Konasi Masy atau prinsip bertransaksi yang berkaitan dengan produk perbankan syariah secara umum sebagai berikut wadiah, musyarakah, mudlarabah, bai' murabahah, bai' salam,bai' bitsaman 'ajil,bai' istishna', ijarah,ijarah muntahiya 
bittamlik,kafalah,wakalah,al-qard al-hasan,sharf (Muhammad, 2000; Ascarya, 2007; Sayafii, 2008; Karim, 2004 ; Zuhaili; 2004).

Schema dalam kamus bahasa Inggris berarti skema atau bagan, scheme berarti rencana atau pola (Echols dan Shadily, 1996). skema merupakan suatu model (Sulistiyaningsih, 2010). Dalam konteks yang lain kata finance dapat dihubungkan dengan financial institution atau lembaga keuangan (Ismaya, 2006). Lembaga yang kegiatan utamanya bergerak di bidang keuangan / finance (Veithzal Rivai dkk, 2007). Finance Scheme (skim keuangan) yang dimaksud adalah skim keuangan yang berkaitan dengan produk bank syariah. Skim keuangan dalam produk bank syariah terdiri dari skim penyimpanan/ penghimpunan dana, skim pembiayaan/ penyaluran dan skim pelayanan jasa (Ascarya: 2007).

Kemauan merupakan kekuatan untuk memilih dan merealisir suatu tujuan. Tujuan adalah titik akhir dari gerakan yang menuju pada sesuatu arah yang kongkrit (Mahfudz, 1986). Gejala kemauan dibagi atas: a) dorongan, b) keinginan c) hasrat d) kecenderungan e) hawa nafsu (Ahmadi, 1982)

Pemasaran sebagai usaha untuk memenuhi kebutuhan dan keinginan para nasabahnya terhadap produk dan jasa (Kashmir, 2008). Pemasaran harus memperhatikan beberapa hal yang berkaitan dengan kebutuhan dan keinginan konsumen atau nasabah yang dibentuk oleh kultur dan kepribadian individu (Kashmir, 2008)

\section{Metodologi Penelitian}

Jenis penelitian yang digunakan dalam penelitian ini adalah jenis penelitian kuantitatif. Sugiyono (2009) memberikan definisi bahwa penelitian kuantitatif adalah jenis penelitian yang berlandaskan pada filsafat positivisme, digunakan untuk meneliti pada populasi atau sampel tertentu yang mana teknik pengambilan sampel pada umumnya dilakukan secara random dengan pengumpulan data menggunakan instrumen penelitian serta menggunakan data yang bersifat kuantitatif/statistik dengan tujuan untuk menguji hipotesis yang telah ditetapkan. Metode penelitian yang dipakai adalah metode survey, dimana penulis menggunakan kuesioner sebagai alat utama dalam pengumpulan data. Penelitian yang menggunakan kuesioner sebagai alat pokok dalam mengumpulkan data dan informasi dari sebagian responden dinamakan penelitian survey (Singarimburi dan Effendi, 2003:39). Sedangkan tingkat eksplanasi (level of explanation) penelitian ini bersifat komparatif (Sugiyono, 2009). Dalam hal ini peneliti menganalisis ada tidaknya perbedaan kemauan masyarakat kota Yogyakarta terhadap penggunaan arabic term (istilah arab) dengan deskripsi finance scheme (skim keuangan) dalam pemasaran produk bank syariah.

Dalam penelitian ini terdapat dua variabel, yaitu variabel independen $(X)$ dan variabel dependen $(Y)$. Variabel independen $(X)$ terdiri dari arabic term (istilah arab) dan deskripsi finance scheme (skim keuangan). Sedangkan variabel dependen (Y) berupa konasi (kemauan).

Adapun kerangka sampling dalam penelitian ini termasuk dalam kategori nonprobability sampling, yakni metode sampling yang tidak memberi peluang sama bagi setiap unsur atau anggota populasi untuk dipilih menjadi sampel (Muhammad, 2008; Soeratno dan Arsyad, 2008; 
Sugiyono, 2009). Adapun jenis nonprobability sampling yang digunakan adalah jenis quota sampling, yaitu teknik untuk menentukan sampel dari populasi yang mempunyai ciri-ciri tertentu sampai jumlah kuota (Sugiyono, 2009; Umar, 2009; Muhammad, 2008). Mantra dan Kasto dalam Singarimbun (1989) menyebutkan bahwa ada empat faktor yang harus dipertimbangkan dalam menentukan besarnya sampel penelitian agar menghasilkan data yang representatif, yaitu: a) derajat keseragaman (degree of homogenity) dari populasi, makin seragam populasi makin kecil sampel yang dapat diambil; b) presisi yang dikehendaki dari penelitian, makin besar presisi makin besar jumlah sampel yang diambil; c) rencana analisa; d) tenaga, biaya dan waktu. Berdasarkan pertimbangan tersebut penulis menentukan jumlah sampel yang digunakan dalam penelitian ini sebanyak 150 responden yang terdiri dari beberapa profesi antara lain pelajar, mahasiswa, karyawan, buruh, pedagang, wiraswasta, pegawai negeri sipil, guru, dosen.

Penelitian ini menggunakan data primer yang diperoleh secara langsung dari masyarakat dengan metode survey dan penyebaran kuesioner. Pengujian validitas dilakukan terhadap kuesioner yang digunakan untuk mengukur variabel penggunaan arabic terms dan deskripsi finance scheme dengan melihat nilai korelasi item dengan skor total seluruh item. Data penelitian ini menggunakan skala semantic differentials dapat digunakan metode pearson correlation dan spearmen's rank correlation dengan bantuan alat ukur SPSS 17, nilai probabilitas yang digunakan untuk menerima atau menolak signifikansi korelasi item variabel dengan skor total adalah alpha cornbach 0,05. Jika nilai signifikansi item lebih besar daripada probabilitasnya maka item tersebut tidak valid. Setelah dilakukan pengujian validitas terhadap penggunaan arabic terms dan deskripsi skim keuangan ternyata tidak ada pertanyaan yang harus dikeluarkan dalam analisa karena kuesioner yang diuji telah memenuhi tingkat signifikansi sebesar 0,05 (Imam Ghozali, 2005). Menurut Sugiyono (2009), syarat penelitian dikatakan valid yaitu; 1) Korelasi product moment lebih besar dari 0,3 atau $(>0,3), 2)$ Korelasi product moment lebih besar dari $r$ tabel atau $>r$ tabel $(\alpha, n-2) /$ dalam SPSS dirumuskan $t / \operatorname{sqrt}\left(d f+t^{* *} 2\right)$

Uji Reliabilitas digunakan untuk mengetahui tingkat kestabilan suatu alat pengukur dalam mengukur suatu gejala dan kejadian. Uji reliabilitas dengan menggunakan koefisien alpha. Perhitungan koefisien alpha memanfaatkan bantuan SPSS 17 dan batas kritis untuk nilai alpha mengindikasikan kuesioner yang reliable adalah nilai Cronbach Alpha $(\alpha)$ $>$ 0,05 (Ghozali, 2005), apabila digunakan untuk mengukur kembali objek yang sama, hasil yang ditunjukkan relatif tidak berbeda. Ada beberapa syarat reliabilitas antara lain:1) Spearmen Brown $>\mathrm{r}$ tabel, 2) Cronbach $\alpha>$ 0,5 atau 0,6 .

Analisis penelitian dilakukan melalui uji two related sample test

Konasi

Masy

161 dengan uji analisis Sign Test, digunakan untuk mengetahui kecenderungan masyarakat kota Yogyakarta terhadap penggunaan Arabic term dan deskripsi finance scheme secara umum. Uji $k$-independent sample test dengan 
uji analisis Kruskal Wallis digunakan untuk mengetahui ada tidaknya perbedaan kemauan masyarakat Kota Yogyakarta terhadap penggunaan Arabic term dan deskripsi finance scheme berdasarkan latarbelakang pendidikan dan jenis profesi. Uji two-independent sample test dengan uji analisis Mann Whitney, digunakan untuk mengetahui perbedaan kemauan masyarakat Kota Yogyakarta terhadap penggunaan Arabic term dan deskripsi finance scheme secara rinci yang terdiri dari; latarbelakang pendidikan agama, umum, agama dan umum, pelajar, mahasiswa, karyawan, buruh, pedagang, wiraswasta, pegawai negeri sipil, guru dan dosen.

\section{Pembahasan Hasil Penelitian}

Hasil penelitian uji two related sample test dengan menggunakan uji analisis sign test atau uji tanda menunjukkan bahwa secara umum masyarakat Kota Yogyakarta lebih menginginkan penggunaan deskripsi finance scheme (deskripsi skim keuangan) dibandingkan dengan penggunaan arabic terms (istilah-istilah arab). Hal ini dapat disebabkan karena penggunaan deskripsi finance scheme lebih mudah dikenal dan dipahami.

Hasil penelitian uji k-independent sample test dengan menggunakan uji analisis Kruskall Wallis menunjukkan bahwa menurut latarbelakang pendidikan tertentu, ada perbedaan konasi (kemauan) masyarakat Kota Yogyakarta terhadap penggunaan arabic terms dan deskripsi finance scheme dalam pemasaran produk bank syariah. Tingkat perbedaan ini disebabkan karena perbedaan latar belakang pendidikan membuat pengetahuan dan cara pandang mereka juga berbeda. Hal itu pula yang menyebabkan mereka berbeda dalam memahami istilah-istilah arab yang kerap kali membingungkan dan butuh penjelasan yang detail. Begitu juga dengan penggunaan deskrispi skim keuangan yang terkadang kurang simpel.

Hasil penelitian uji k-independent sample test dengan menggunakan uji kruskall wallis menunjukkan bahwa menurut jenis profesi tertentu ada perbedaan konasi (kemauan) masyarakat Kota Yogyakarta terhadap penggunaan arabic terms (istilah-istilah arab) dan penggunaan deskripsi finance scheme (deskripsi skim keuangan) dalam pemasaran produk bank syariah.

Hasil penelitian uji two-independent sample test (uji dua sampel independen) dengan menggunakan analisis type Mann-Whitney menunjukkan bahwa masyarakat Kota Yogyakarta yang berlatarbelakang pendidikan agama lebih menginginkan penggunaan deskripsi finance scheme (deskripsi skim keuangan) dibandingkan arabic terms (istilah-istilah arab) dalam pemasaran produk bank syariah. Hal ini dikarenakan pengetahuan agama yang mereka dapatkan kurang sepenuhnya memberikan pemahaman mendalam terhadap istilah arab yang diterapkan dalam perbankan syariah. Dengan kata lain istilah arab dalam perbankan syariah merupakan istilah arab aplikatif yang tidak lepas dari kajian fiqih muamalah. Hal itu juga dapat berarti pengetahuan agama atau latarbelakang pendidikan agama bukan jaminan seseorang untuk mudah memahami istilah arab dalam perbankan syariah.

Abdul

Ghani

162 
Hasil penelitian uji two-independent sample test (uji dua sampel independen) dengan menggunakan analisis type Mann-Whitney menunjukkan bahwa masyarakat Kota Yogyakarta yang berlatarbelakang pendidikan umum lebih menginginkan penggunaan deskripsi finance scheme (deskripsi skim keuangan) yang diungkapkan dengan uraian berbahasa Indonesia dibandingkan penggunaan arabic terms (istilah-istilah arab) dalam pemasaran produk bank syariah. Masyarakat dalam kategori ini termasuk sampel yang paling banyak.

Hasil penelitian uji two-independent sample test (uji dua sampel independen) dengan menggunakan analisis type Mann-Whitney menunjukkan bahwa masyarakat Kota Yogyakarta yang berlatarbelakang pendidikan agama dan umum lebih menginginkan penggunaan arabic terms (istilah-istilah arab) dibanding penggunaan deskripsi finance scheme (deskripsi skim keuangan) yang diungkapkan dengan uraian berbahasa Indonesia dalam pemasaran produk bank syariah. Hal ini disebabkan pemahaman mereka terhadap produk bank syariah telah diperoleh melalui beberapa pertimbangan, baik pertimbangan sistem maupun media informasi. Namun demikian berdasarkan tabel yang ada prosentase kategori ini sangat kecil.

Hasil penelitian uji two-independent sample test (uji dua sampel independen) dengan menggunakan analisis type Mann-Whitney menunjukkan bahwa masyarakat Kota Yogyakarta yang berprofesi sebagai pelajar/mahasiswa lebih menginginkan penggunaan arabic terms (istilahistilah arab) dibandingkan dengan penggunaan deskripsi finance scheme (deskripsi skim keuangan) yang diungkapkan dengan uraian berbahasa Indonesia dalam pemasaran produk bank syariah.

Hasil penelitian uji two-independent sample test (uji dua sampel independen) dengan menggunakan analisis type Mann-Whitney menunjukkan bahwa masyarakat Kota Yogyakarta yang berprofesi sebagai karyawan/buruh lebih menginginkan penggunaan deskripsi finance scheme (deskripsi skim keuangan) dibandingkan dengan penggunaan arabic terms (istilah-istilah arab) dalam pemasaran produk bank syariah.\

Hasil penelitian uji two-independent sample test (uji dua sampel independen) dengan menggunakan analisis type Mann-Whitney menunjukkan bahwa masyarakat Kota Yogyakarta yang berprofesi sebagai pedagang/wiraswasta lebih menginginkan penggunaan deskripsi finance scheme (deskripsi skim keuangan) yang diungkapkan dengan uraian berbahasa Indonesia dibanding dengan penggunaan arabic terms (istilahistilah arab) dalam pemasaran produk bank syariah.

Hasil penelitian uji two-independent sample test (uji dua sampel independen) dengan menggunakan analisis type Mann-Whitney menunjukkan bahwa masyarakat Kota Yogyakarta yang berprofesi sebagai pegawai negeri sipil (PNS) lebih menginginkan penggunaan deskripsi finance scheme (deskripsi skim keuangan) yang diungkapkan dengan uraian berbahasa Indonesia dibanding dengan penggunaan arabic terms (istilahistilah arab) dalam pemasaran produk bank syariah. 
Hasil penelitian uji two-independent sample test (uji dua sampel independen) dengan menggunakan analisis type Mann-Whitney menunjukkan bahwa masyarakat Kota Yogyakarta yang berprofesi sebagai dosen/guru lebih menginginkan penggunaan deskripsi finance scheme (deskripsi skim keuangan) yang diungkapkan dengan uraian berbahasa Indonesia dibanding penggunaan arabic terms (istilah-istilah arab) dalam pemasaran produk bank syariah.

\section{E. Kesimpulan dan Saran}

Berdasarkan hasil penelitian dan pembahasan, maka dapat ditarik kesimpulan sebagai berikut:

1. Terdapat perbedaan konasi (kemauan dan keinginan) di kalangan masyarakat Kota Yogyakarta terhadap penggunaan arabic terms (istilah arab) dan deskripsi finance schema (skim keuangan) dalam pemasaran produk bank syariah. Perbedaan tersebut dapat dilihat baik berdasarkan latarbelakang pendidikan (pendidikan agama, pendidikan umum, serta pendidikan agama dan umu), maupun dilihat berdasarkan jenis pekerjaan/profesi (pelajar/mahasiswa, karyawan/buruh, pedagang/wiraswasta, PNS, dan dosen/guru).

2. Secara umum masyarakat Kota Yogyakarta lebih menginginkan penggunaan deskripsi finance schema (skim keuangan) yang dipaparkan dengan istilah-istilah berbahasa Indonesia dibandingkan dengan penggunaan arabic terms (istilah-istilah arab) dalam pemasaran dan sosialisasi produk-produk bank syariah.

Berdasarkan hasil penelitian dan kesimpulan di atas, maka penulis memberikan saran sebagai bentuk implementasi dari penelitian ini sebagai berikut:

1. Dalam pemasaran produk-produknya, hendaknya bank syariah tidak menggeneralisasikan persepsi dan kemauan masyarakat. Selayaknya persepsi mereka terhadap pemahaman istilah-istilah yang digunakan dalam label produk bank syariah dipertimbangkan dengan cermat. Hal ini dimaksudkan supaya masyarakat lebih mengenal dan memahami produk bank syariah. Jika masyarakat telah mengenal produk-produk bank syariah, diharapkan mereka mudah memiliki kemauan untuk menjadi nasabah.

2. Melihat hasil penelitian maka bank syariah selayaknya tidak lagi melakukan arabisasi secara mutlak terhadap produk-produknya. Karena pada kenyataannya masyarakat sebagai pasar sangat sedikit yang memahami dan mengenali istilah-istilah arab. Mereka lebih familier dengan deskripsi finance schema (skim keuangan) yang diungkapkan dengan istilah berbahasa Indonesia. 


\section{DAFTAR PUSTAKA}

Ahmadi, Abu. 1982. Psikologi Umum, Surabaya: PT. Bina Ilmu.

Arikunto, Suharsimi. 2006. Prosedur Penelitian Suatu Pendekatan Praktik, Edisi 6. Jakarta: PT. Rineka Cipta

Ascarya. 2007. Akad dan Produk Bank Syariah. Jakarta: PT. RajaGrafindo Persada

Buchori, Nur. S. 2009. Koperasi Syariah. Sidoarjo: Mashun

Buletin. 2007. Preferensi Masyarakat Terhadap Bank Syariah di Indonesia. Yogykarta: Buletin Ie Bishawab Laboratorium Ekonomika dan Bisnis Islam (LEBI) UGM

Ellitan, Lena dan Lina Anatan. 2009. Manajemen Inovasi Transformasi Menuju Organisasi Kelas Dunia. Bandung: Alfabeta, CV

Hamidi, Jazim dkk. 2000. Persepsi dan Sikap Masyarakat Santri Jawa Timur Terhadap Bank Syariah di Wilayah Jawa Timur. Penelitian, tidak dipublikasikan

Harjasujana, Ahmad S. dkk. 1986. Buku Materi Pokok Keterampilan Membaca. Jakarta: Karunia, Universitas Terbuka.

Harjasujana, Ahmad S. dkk. 1988. Nusantara yang Literat; Secercah Sumbang Saran terhadap Upaya Peningkatan Mutu Pendidikan Indonesia. Bandung: IKIP Bandung.

Ismaya, Sujana. 2006. Kamus Perbankan. Bandung: Pustaka Grafika

Kartajaya, Hermawan dan M. Syakir Sula. 2008. Syariah Marketing. Bandung: PT. Mizan Pustaka

Kasmir. 2004. Pemasaran Bank. Jakarta: Kencana Prenada Media Group

Kuncoro, Mudrajad. 2007. Metode Kuantitatif Teori dan Aplikasi Untk Bisnis dan Ekonomi. Yogyakarta: UPP STIM YKPN

Mahfudz, Shalahudin. 1986. Pengantar Psikologi Umum. Surabaya "Sinar Wijaya"

Muhammad. 2005. Manajemen Bank Syariah. Yogyakarta: UPP STIM YKPNK

Muhammad. 2008. Metodologi Penelitian Ekonomi Islam Pendekatan Kuantitatif. Jakarta: PT. RajaGrafindo Persada

Penelitian. 2000. Potensi, Prefensi dan Prilaku Masyarakat Terhadap Bank Syariah di Wilayah Jawa Tengah dan DI. Yogyakarta. Semarang: Bank Indonesia dan Pusat Penelitian Kajian Pembangunan Lembaga Penelitian Universitas Diponegoro

Penelitian. 2001. Potensi, Prefensi dan Prilaku Masyarakat Terhadap Bank Syariah di Sumatera Barat. Padang: Bank Indonesia Padang dan Lembaga Penelitian Universitas Andalas

Prabawati, Th. Ari. 2010. Mengolah Data Statistik Hasil Penelitian Dengan SPSS 17. Yogyakarta: CV. Andi Offset

Purwanto, M. Ngalim. 2003. Psikologi Pendidikan. Bandung: PT. Remaja Rosdakarya

Konasi

Masy

165
Rumini, Sri. 1993. Psikologi Pendidikan. Yogyakarta: Unit Percetakan dan Penerbitan Universitas Negeri Yogyakarta 
Saleh, Samsubar. 1996. Statistik Nonparametrik. Yogyakarta: BPFEYogyakarta

Singarumbun, dan Sofian Effendi. 1989. Metode Penelitian Survei. Jakarta: 00LP3ES

Soemanto, Wasty. Psikologi Pendidikan (Landasan Kerja Pemimpin Pendidikan). Jakarta: PT. Bina Aksara

Soertano, dan Lincolin Arsyad. 2008. Metodologi Penelitian Untuk Ekonomi dan Bisnis. Yogyakart: UPP STIM YKPN

Sudarsono, Heri. 2003. Bank dan Lembaga Keuangan Syariah Deskripsi dan Ilustrasi. Yogyakarta: Ekononisia FE UII

Sugiyono. 2009. Metode Penelitian Bisnis (Pendekatan Kuantitatif, Kualitatif, R \& D). Bandung: CV. Alfabeta

Sujanto, Agus. 2001. Psikologi Umum. Jakarta: Bumi Aksara

Tampubolon, D.P. 1987. Kemampuan Membaca, Teknik Membaca Efektif dan Efisien. Bandung: Angkasa.

Trihendradi, Cornelius. 2007. Langkah Mudah Menguasai Analisis Statistik Menggunakan SPSS 15. Yogyakarta: CV. Andi Offset

Umar, Husein. 2009. Metode Penelitian Untuk Skripsi dan Tesis, Edisi 2. Jakarta: PT. Raja Grafindo Persada

Umar, Husen. 2002. Metode Riset Bisnis. Jakarta: PT. Gramedia Pustaka Utama

Uyanto, Stanislaus S. 2009. Pedoman Analisis Data Dengan SPSS. Yogyakarta: Graha Ilmu

Wahjono, Sentot Imam. 2010. Manajemen Pemasaran Bank. Yogyakarta: Graha Ilmu

Wirdyaningsih, dkk. 2005. Bank dan Asuransi Islam di Indonesia. Jakarta: Kencana 